\section{BMJ Paediatrics Open}

\title{
Evaluation of a continuous neonatal temperature monitor for low-resource settings: a device feasibility pilot study
}

Sonia E. Sosa Saenz, ${ }^{1}$ Mary Kate Hardy, ${ }^{1}$ Megan Heenan, ${ }^{1}$ Z. Maria Oden, ${ }^{1,2}$ Rebecca Richards-Kortum (D) , 1,2 Queen Dube, ${ }^{3,4}$ Kondwani Kawaza,4

\section{ABSTRACT}

Objective Evaluate a novel continuous temperature monitor in a low-resource neonatal ward.

Design We developed a low-cost continuous neonatal temperature monitor (NTM) for use in low-resource settings. Accuracy of NTM was initially assessed in the laboratory. Clinical evaluation then was performed in a neonatal ward in a central hospital in Malawi; eligible neonates ( $<1$ week of age) were recruited for continuous temperature monitoring with NTM and a Philips Intellivue MP30 Patient Monitor.

Interventions and outcome measures The temperature probes of NTM and the reference patient monitor were attached to the infant's abdomen, and core temperature was continuously recorded for up to 3 hours. Axillary temperatures were taken every hour. We compared temperatures measured using NTM, the patient monitor and the axillary thermometer.

Results Laboratory temperature measurements obtained with NTM were within $0.059^{\circ} \mathrm{C}$ (range: $-0.035^{\circ} \mathrm{C}$ to $0.195^{\circ} \mathrm{C}$ ) of a reference thermometer. A total of 39 patients were recruited to participate in the clinical evaluation of NTM; data from four patients were excluded due to faulty hardware connections. The mean difference in measured temperatures between the NTM and the Intellivue MP30 was $-0.04^{\circ} \mathrm{C}\left(95 \% \mathrm{Cl}-0.52^{\circ} \mathrm{C}\right.$ to $\left.0.44^{\circ} \mathrm{C}\right)$.

Conclusion NTM meets ISO 80601-2-56 standards for accuracy and is an appropriate, low-cost continuous temperature monitor for neonatal wards in low-resource settings.

Trial registration numbers NCT03965312 and NCT03866122.

${ }^{1}$ Rice $360^{\circ}$ Institute for Global Health, Rice University, Houston, Texas, USA

${ }^{2}$ Department of Bioengineering, Rice University Department of Bioengineering, Houston, Texas, USA

${ }^{3}$ Department of Pediatrics, University of Malawi College of Medicine, Blantyre, Southern Region, Malawi

${ }^{4}$ Department of Pediatrics, Queen Elizabeth Central Hospital, Blantyre, Southern Region, Malawi

Correspondence to Dr Rebecca Richards-Kortum; rkortum@rice.edu

\section{INTRODUCTION}

Neonatal hypothermia-broken down into three levels by the WHO (mild: $36^{\circ} \mathrm{C}-36.5^{\circ} \mathrm{C}$; moderate: $32^{\circ} \mathrm{C}-35.9^{\circ} \mathrm{C}$; and severe: $\left.<32^{\circ} \mathrm{C}^{1}\right)-$ is a significant global challenge, especially for premature and sick babies. ${ }^{2}$ Hypothermia is common in countries with high neonatal mortality rates, and managing hypothermia has been recognised as crucial to improve survival. ${ }^{3}$ The reported incidence of neonatal hypothermia in low-income and middle-income countries ranges from $25 \%$ to $85 \% .^{245}$

Hypothermia alone increases an infant's chance of death. ${ }^{2}{ }^{6}$ If left untreated,

\section{What is known about the subject?}

Neonatal hypothermia is a significant contributor to infant mortality in low-resource settings.

- Appropriate temperature-monitoring tools are unavailable in low-resource settings, leading to undermonitoring of infants and low awareness of hypothermia.

- Currently available temperature-monitoring tools are too expensive, inaccurate or insufficient to address the need for quantitative temperature measuring tools for use in low-resource settings.

\section{What this study adds?}

- We report the design and development of a lowcost, robust and reusable continuous temperaturemonitoring system for neonates in low-resource settings.

- The clinical performance of this novel device is comparable with a clinically available patient monitor used in high-income countries.

- This device received positive feedback from clinical staff in the neonatal ward of Queen Elizabeth Central Hospital in Blantyre, Malawi.

hypothermia can additionally result in significant comorbidity, increasing the risk of mortality due to other common newborn conditions. ${ }^{4} 7$ Persistent hypothermia in newborns can lead to complications such as infection, hypoglycaema and metabolic acidosis, and increase the risk of late-onset sepsis. ${ }^{78}$ The adjusted mortality risk increases $28 \%-80 \%$ for every $1{ }^{\circ} \mathrm{C}$ decrease in first observed axillary temperature,${ }^{589}$ with babies $<35.0^{\circ} \mathrm{C}$ experiencing a sixfold increase in mortality. ${ }^{5}$ Persistent hypothermia can also reduce the effectiveness of treatment for other newborn conditions. For example, a study of neonates with respiratory distress showed that mean temperature during treatment was the strongest predictor of survival to discharge. ${ }^{10}$ 
In high-resource settings, neonatal temperature is monitored continuously using commercially available patient monitors (PMs). These devices cost thousands of dollars, require delicate sensors and expensive consumable stickers and are not designed to withstand the harsh environmental conditions in low-resource settings (LRS). Existing low-cost temperature monitoring devices that could be used in low-income countries, while sensitive enough to detect hypothermia, do not have the features necessary to guide clinicians in a hospital setting. ${ }^{11-13}$ The current standard of care for temperature monitoring in LRS is axillary temperature taken every 4 hours (for highrisk infants) and 12 hours (for low-risk infants), ${ }^{1}$ which can be difficult to implement in short-staffed wards, leaving infants unmonitored for long periods of time.

Kangaroo Mother Care (KMC) is an effective method of thermoregulation in LRS, and it has been shown to improve thermal stability in preterm newborns. ${ }^{14}$ It confers other benefits on both mother and child such as improved survival rates, reduced rates of infection, stabilised respiratory rate and improved maternalchild bonding. ${ }^{15-17}$ However, the lack of temperaturemonitoring tools in the neonatal ward can lead to early discharge of babies who otherwise might be recommended for KMC.

Although KMC is an effective treatment for hypothermia, it is not appropriate for every infant. The WHO recommends KMC be initiated as soon as possible in clinically stable newborns. However, newborns who are not clinically stable remain in the NICU (Neonatal Intensive Care Unit) for monitoring and treatment. ${ }^{18}$ The lack of continuous temperature monitoring in the neonatal wards can be particularly dangerous for preterm infants; they are susceptible to hypothermia and thermal shock (caused by rapid, frequent heating/cooling), which can cause death. ${ }^{6}$ Combined with ward overcrowding and understaffing, hypothermia remains a largely invisible problem in newborn units in LRS, especially when the baby shows no visible symptoms.

The current standard of care in LRS is insufficient to address these challenges. There is an unmet need for an accurate temperature-monitoring tool designed specifically for LRS that can continuously monitor the infant's temperature and effectively alert hospital staff when intervention is needed. An ideal temperature monitor should: (1) monitor continuously, (2) be accurate $\left( \pm 0.5^{\circ} \mathrm{C}\right.$ clinical accuracy), (3) not require consumables and (4) be easy to use, robust and affordable. The objective of this pilot study was to carry out laboratory and clinical evaluations to determine whether this novel neonatal temperature monitor (NTM), designed specifically for use in LRS, meets these criteria.

\section{METHODS}

\section{Device development}

We developed a low-cost NTM for use in LRS. Figure 1 shows the three major components of the device: (1) a reusable temperature probe; (2) a reusable belt that holds the temperature probe on the baby's skin; and (3) a monitor that displays the baby's core temperature with indicator lights to signal whether the baby is hypothermic $\left(<36.5^{\circ} \mathrm{C}\right.$; blue warning light $)$, normothermic $\left(36.5^{\circ} \mathrm{C}-37.5^{\circ} \mathrm{C}\right.$; green indicator light) or hyperthermic $\left(>37.5^{\circ} \mathrm{C}\right.$; red warning light).

Temperature probe: the temperature probe consists of a medical-grade thermistor in a stainless-steel housing and a plastic backing (figure 1, inset). The thermistor, housing and backing are joined with thermally conductive epoxy. The probe is attached to the belt with snaps embedded in the backing. The snaps allow easy attachment/removal of the temperature probe to the abdominal belt and ensure proper positioning of the probe.

Belt: the temperature probe is held in contact with the skin above the liver using an adjustable belt made of easyto-clean nylon fabric. Elastic is sewn into the belt, so it fits snugly and comfortably. A shoulder strap runs from the back of the belt, over the infant's shoulder and down the chest to prevent slipping. All seams are covered with fabric to reduce the possibility of skin irritation.

Monitor: the monitor contains an Arduino Uno microcontroller (Arduino, Massachusetts, USA), which converts thermistor resistance to temperature. The microcontroller displays the temperature in ${ }^{\circ} \mathrm{C}$ (to $0.1^{\circ} \mathrm{C}$ ) on a seven-segment display and controls indicator lights corresponding to the baby's thermal state; both are updated at $1 \mathrm{~Hz}$.

\section{Laboratory validation of NTM}

Prior to the clinical study, laboratory accuracy tests were performed to validate that NTM meets ISO 80601-2-56 referent to clinical thermometers for body temperature measurements. ${ }^{19}$ Three temperature probes were tested with three NTM devices against a reference thermometer OAKTON Temp 340 (OAKTON Instruments, Illinois, USA). Each probe was tested with each NTM for a total of $3 \times 3$ tests. Laboratory accuracy was tested by submerging the probes for NTM and reference thermometer in a water bath of known temperature, letting probes stabilise for $30 \mathrm{~min}$, and performing a discrete temperature measurement at each temperature. The tests were performed at three known temperatures $\left(31.0^{\circ} \mathrm{C}, 36.0^{\circ} \mathrm{C}\right.$ and $41.0^{\circ} \mathrm{C}$ ).

\section{Clinical evaluation of NTM \\ Ethics statement}

We conducted a pilot study to evaluate the accuracy of NTM compared with a standard, commercially available PM at Queen Elizabeth Central Hospital (QECH) in Blantyre, Malawi. The trial is registered at ClinicalTrials. gov.

\section{Patient and public involvement}

There were no patients or public involved in the research design, process and research findings dissemination. 


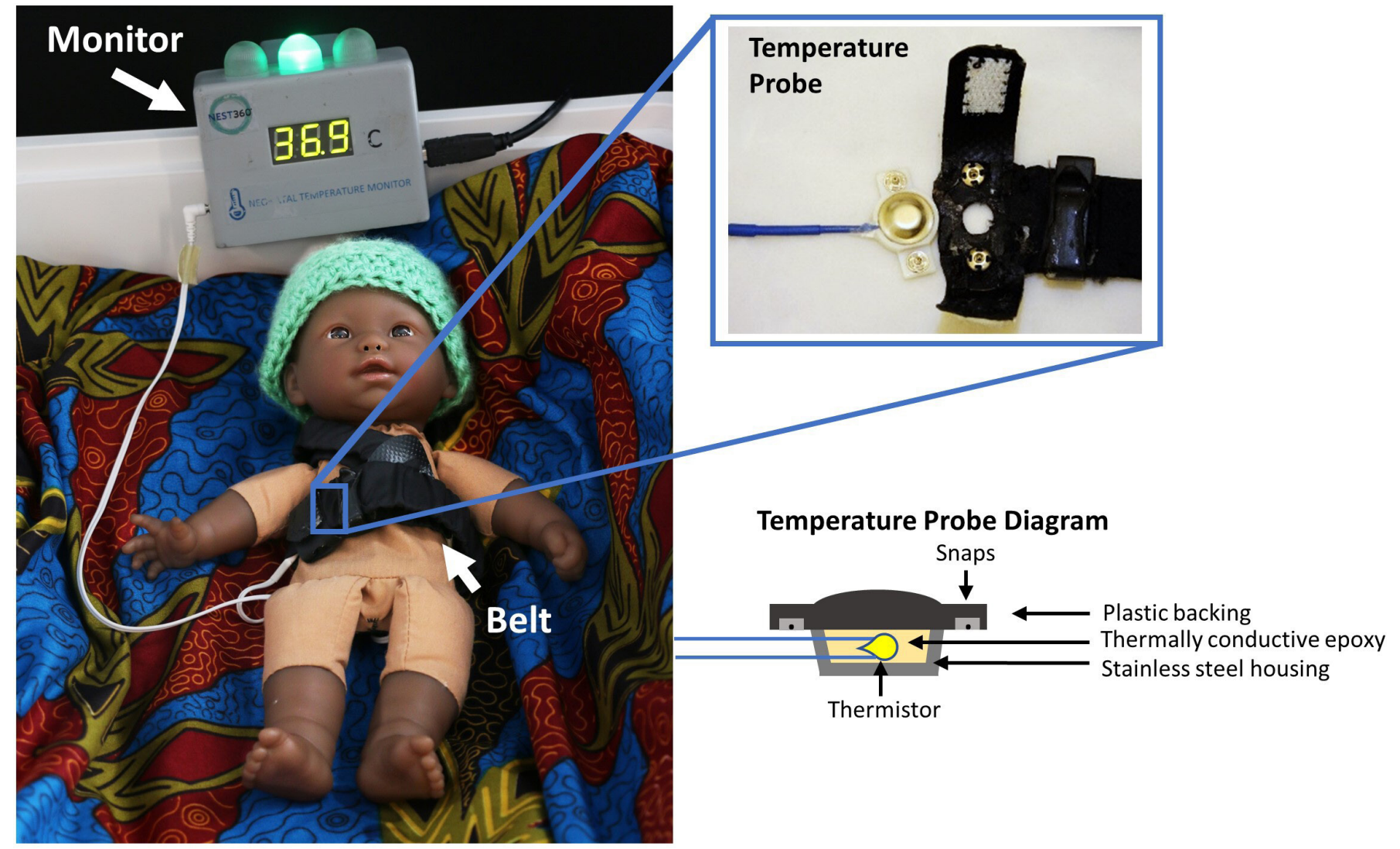

Figure 1 NTM is composed of three major components: (1) a temperature probe, (2) a reusable belt and (3) a monitor. The temperature probe is held over the liver by a belt with shoulder strap. The monitor displays the infant's core temperature in ${ }^{\circ} \mathrm{C}$ with visual indicators corresponding to hypothermia, normothermia and hyperthermia. The reusable temperature probe snaps into the belt. NTM, neonatal temperature monitor.

Prior to enrolment, a trained nurse identified potential eligible patients. Written informed consent was obtained from the parents or guardians of all participants involved in this study. Eligible patients included any neonate: (1) in stable condition; (2) located in the low-risk unit of the neonatal ward; and (3) whose parents or guardians provided informed consent. A minimum of 35 subjects, with no less than $30 \%$ and no greater than $50 \%$ febrile subjects, were needed in accordance to ISO 80601-2-56 human subject population requirements. The standard requires at least 35 subjects in the group A1, 0 up to 3 months, for clinical accuracy validation. ${ }^{19}$ Recruitment continued until the pre-established sample size was reached.

All enrolled patients were in cots open to room air, the current standard of care in the low risk unit. Some patients were receiving thermal care and/or phototherapy. Patients were monitored using NTM and a Philips IntelliVue Patient Monitor MP30 (Philips, Amsterdam, Netherlands). The Philips MP30 and its corresponding reusable temperature probe was used as a gold standard. The NTM and PM probes were attached to each infant using the reusable belt and a reflective sticker, respectively. The NTM probe was placed over the patient's liver, and the temperature probe of the PM was placed as close as possible to the NTM probe. Temperature data were logged for up to 3 hours on each patient. Axillary temperature, the standard of care for temperature monitoring at QECH, was also measured by the study nurse using a digital thermometer (Generation Guard, New York, USA) every hour. Probes and the NTM belt were disinfected between each patient using methylated spirits (95\% ethanol, 5\% methanol). A researcher observed all patients during the entire period of data collection.

Clinicians and nurses who staffed the ward during the study were asked to provide feedback about NTM.

\section{Data analysis}

Participant demographics and relevant variables were obtained from the infant's medical records. Continuous temperature data from NTM were collected using CoolTerm, an open-source serial port data-logging application. Temperature signals from the PM were collected through MediCollector BEDSIDE (MediCollector, Massachusetts, USA). Axillary temperatures were manually collected and recorded in an Excel spreadsheet (Microsoft, Washington, USA) for comparison. Analysis was performed in Excel and MATLAB 2017 (MathWorks, Massachusetts, USA).

To compare continuous and discrete temperature values, a single time point from the continuous measurement at the 1, 2 and 3 hour marks was chosen and entered 
in the Excel spreadsheet. Bland Altman plots, bias (mean difference) and 95\% CI limits of agreement (LOAs) were used to compare the agreement between the NTM device readings with the PM readings, as well as compare the NTM and PM readings with standard of care axillary temperature readings.

\section{Patient and public involvement}

Patients and/or the public were not involved in the design, or conduct, or reporting, or dissemination plans of this research.

\section{RESULTS}

The NTM device monitor measures $100 \times 42 \times 73 \mathrm{~mm}$, and the materials cost to fabricate an in-house prototype is $\$ 80$.

\section{Laboratory validation of NTM}

Nine measurements were performed with each probe (one measurement per NTM per temperature) for a total of 27 analysed measurements. The mean error across all NTM devices and probes was $0.059^{\circ} \mathrm{C}$ (range: $-0.035^{\circ} \mathrm{C}$ to $0.195^{\circ} \mathrm{C}$ ). For complete table, refer to online supplementary SI1.

\section{Clinical evaluation of NTM}

A total of 39 subjects were recruited from the neonatal ward low-risk unit at QECH. Of the 39 subjects, four were excluded from analysis for the following reasons: a bad connection between the device and logging computer (two subjects); a faulty connection between the probe and device (one subject); and an improperly tightened belt that did not remain in place during data collection (one subject). Subject characteristics are summarised in table 1. A Consolidated Standards of Reporting Trials flow chart is provided in figure 2. Of analysed subjects, $63 \%$ were male. Gestational ages ranged from 32 weeks to 38 weeks (mean: 36 weeks). All infants were $<1$ week of age at the time of the study. Infants weighed between $1.12 \mathrm{~kg}$ and $3.80 \mathrm{~kg}$ (mean: $2.43 \mathrm{~kg}$ ). On admission to the ward, 11 infants were moderately hypothermic $\left(32.0^{\circ} \mathrm{C}-35.9^{\circ} \mathrm{C}\right)$; 7 were mildly hypothermic $\left(36.0^{\circ} \mathrm{C}-36.4^{\circ} \mathrm{C}\right) ; 4$ were normothermic $\left(36.5^{\circ} \mathrm{C}-37.5^{\circ} \mathrm{C}\right)$; and 11 were hyperthermic $\left(>37.5^{\circ} \mathrm{C}\right)$. Hyperthermic infants were preferentially selected to meet ISO testing standards. ${ }^{19}$

Figure 3 shows a photo of the study setup and placement of the temperature probes on a subject. Seven of 39 subjects exhibited minor indentations from the belt; none of the subjects exhibited skin irritation. Figure 4A,B shows two typical examples of continuous temperature data from NTM and the commercial PM. Temperature measured by NTM is shown as a solid line; temperature measured by the PM is shown as a dashed line. A difference of $\pm 0.5^{\circ} \mathrm{C}$ from the PM temperature is shown as a dotted line. Discrete axillary temperature measurements are indicated by diamonds. The x-axis time (min) refers to the elapsed time of the temperature
Table 1 Subjects characteristics

Number of subjects

\begin{tabular}{|c|c|c|}
\hline Gender & \multicolumn{2}{|c|}{$\begin{array}{c}\text { Male: } 22(63 \%) \\
\text { Female: } 13(37 \%)\end{array}$} \\
\hline $\begin{array}{l}\text { Mean gestational } \\
\text { age }\end{array}$ & \multicolumn{2}{|c|}{$\begin{array}{l}36.3 \text { weeks (32-38) } \\
\text { Unknown: } 4(11.4 \%)\end{array}$} \\
\hline \multirow[t]{5}{*}{ Mean weight $(\mathrm{kg})$} & \multicolumn{2}{|c|}{$2.43 \mathrm{~kg}(1.12-3.80)$} \\
\hline & $\leq 1.5 \mathrm{~kg}$ & $4(11.4 \%)$ \\
\hline & $>1.5$ to $\leq 2.5 \mathrm{~kg}$ & $11(31.4 \%)$ \\
\hline & $>2.5 \mathrm{~kg}$ & $17(48.6 \%)$ \\
\hline & Unknown & $3(8.6 \%)$ \\
\hline \multirow{7}{*}{$\begin{array}{l}\text { Mean admission } \\
\text { temperature }\left({ }^{\circ} \mathrm{C} \text {, }\right. \\
\text { axillary with digital } \\
\text { thermometer) }\end{array}$} & \multicolumn{2}{|c|}{$36.6^{\circ} \mathrm{C}(34.6-39.3)$} \\
\hline & $\begin{array}{l}<32^{\circ} \mathrm{C} \text { (severe } \\
\text { hypothermia) }\end{array}$ & $0(0 \%)$ \\
\hline & $\begin{array}{l}\geq 32-<35.9^{\circ} \mathrm{C} \\
\text { (moderate } \\
\text { hypothermia) }\end{array}$ & $11(31.4 \%)$ \\
\hline & $\begin{array}{l}\geq 36-<36.5^{\circ} \mathrm{C} \text { (mild } \\
\text { hypothermia) }\end{array}$ & $7(20.0 \%)$ \\
\hline & $\begin{array}{l}\geq 36.5-<37.5^{\circ} \mathrm{C} \\
\text { (normothermic) }\end{array}$ & $4(11.4 \%)$ \\
\hline & $\begin{array}{l}\geq 37.5^{\circ} \mathrm{C} \\
\text { (hyperthermic) }\end{array}$ & $11(31.4 \%)$ \\
\hline & Unknown & $2(5.7 \%)$ \\
\hline
\end{tabular}

monitoring of a participant. A subset of the data is shown to highlight temperature tracking between both devices with significant resolution. In both examples, temperature measurements made using NTM are within $\pm 0.5^{\circ} \mathrm{C}$ of the measurements made by the PM and axillary

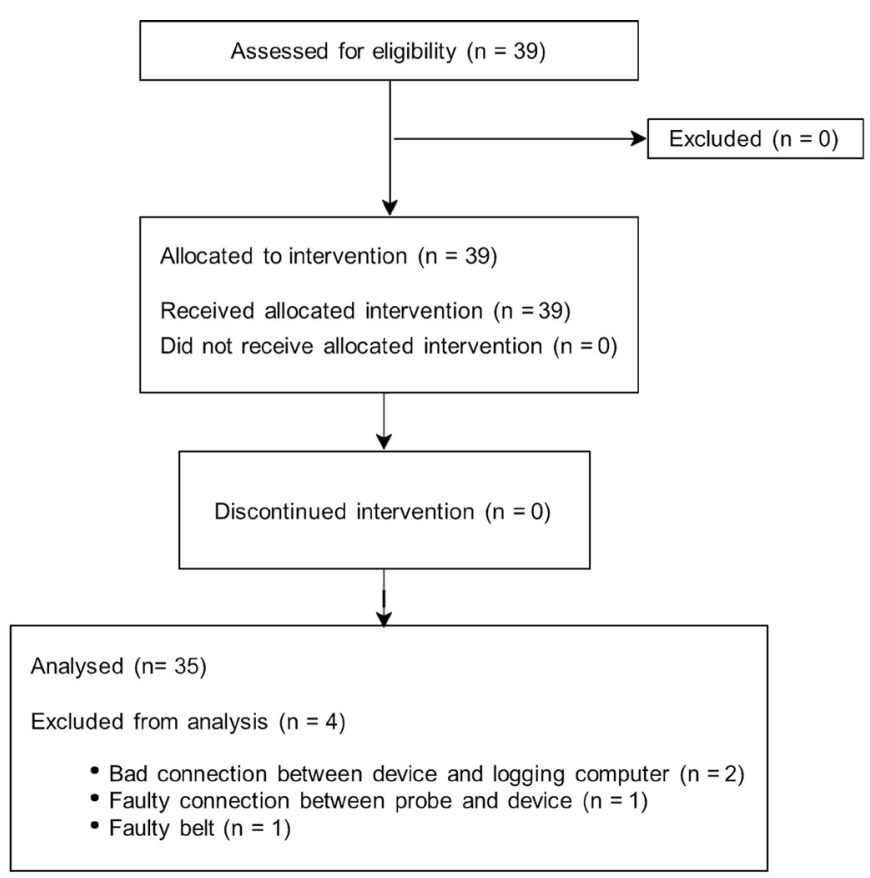

Figure 2 CONSORT flow diagram. CONSORT, Consolidated Standards of Reporting Trials. 

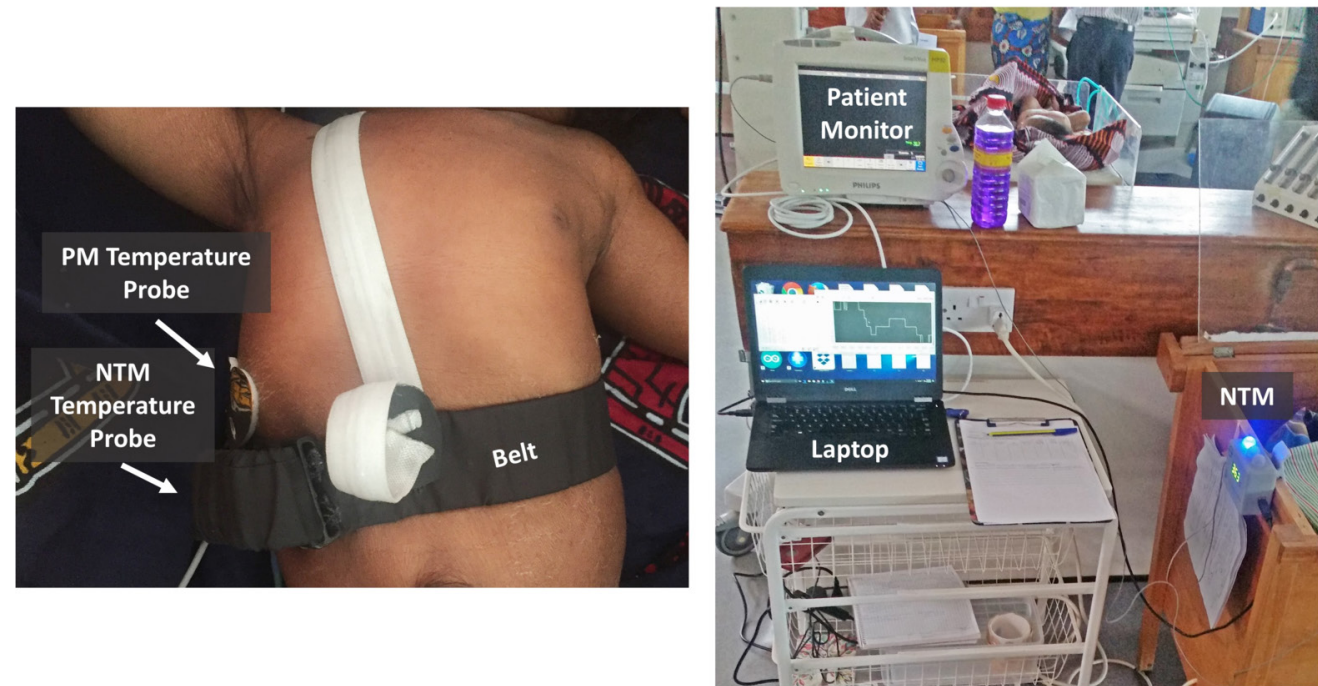

Figure 3 Clinical evaluation setup. During testing, the abdominal belt was placed around the infant, positioning the temperature probe above the liver. A commercial patient monitor (PM) and temperature sensor were used as the gold standard. All data were recorded using logging software. NTM, neonatal temperature monitor.

measurements. During nursing (figure $4 \mathrm{~A}$, right), the infant's temperature rises, a feature that is captured by both PM and NTM measurements.

Figure 4C,D shows Bland-Altman plots comparing temperature measured with the NTM to that measured with the PM using discrete data points at 1-hour, 2-hour and 3-hour intervals for all subjects. The 95\% CI-LOA $( \pm 1.95 \mathrm{~s})$ are $-0.52^{\circ} \mathrm{C}$ to $0.44^{\circ} \mathrm{C}$ with a bias of $-0.04^{\circ} \mathrm{C}$.
The bias of the NTM vs PM in clinical testing is comparable with the average error between NTM and a reference thermometer observed during laboratory accuracy testing. Figure 4C,D show Bland-Altman plots comparing the PM and the NTM measurements to axillary temperature measurements. Both the PM and NTM measured slightly higher on average than axillary temperatures by $0.11(95 \% \mathrm{CI}-0.49 \text { to } 0.80)^{\circ} \mathrm{C}$ and $0.15(95 \%$ CI -0.66
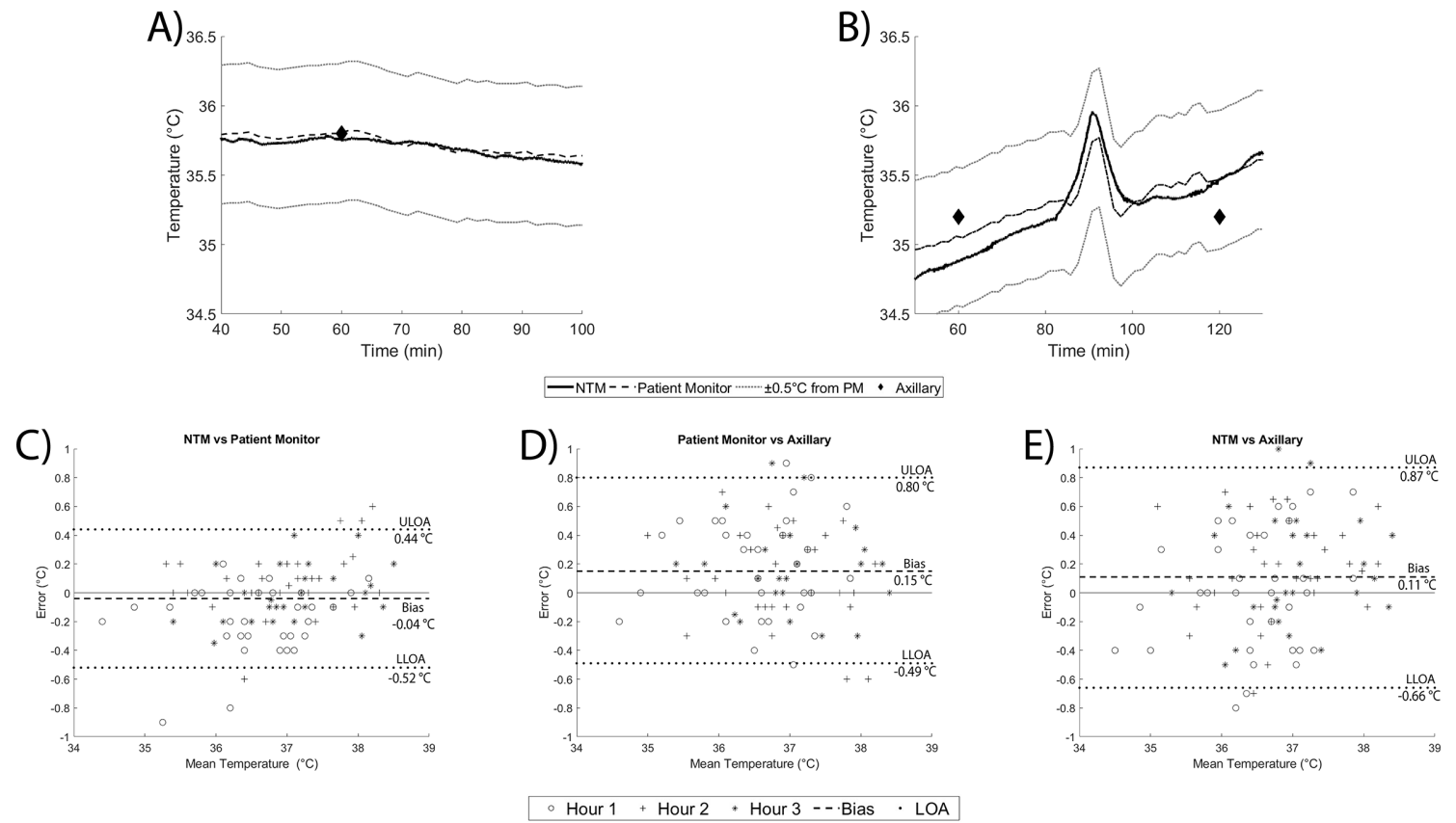

Figure 4 Top: examples of recorded signals. NTM (solid line) and PM (dashed line) signals were continuously recorded throughout the study. Axillary measurements (black diamonds) were collected every hour. (A) An example showing constant core temperature. (B) An example during nursing. An increase in the subject's temperature is observed during nursing, shown by both PM and the NTM device. In both recordings, NTM signal was within $\pm 0.5^{\circ} \mathrm{C}$ (dotted line) of the PM and axillary temperatures. Bottom: Bland-Altman plots comparing the temperatures recorded from (C) NTM and PM, (D) PM and axillary measurement and (E) NTM and axillary measurement. Biases are shown using a dashed line. Ninety-five per cent Cl upper and lower limits of agreement (ULOA and LLOA, respectively) are shown using a dotted line. NTM, neonatal temperature monitor; PM, patient monitor. 
to 0.87$)^{\circ} \mathrm{C}$, respectively. For more information, refer to online supplementary SI3.

\section{DISCUSSION}

NTM provides real-time digital monitoring of neonatal temperature together with indicator lights signalling hypothermia and hyperthermia. The accuracy of NTM is comparable with continuous temperature monitoring using commercially available PMs commonly used in high-resource settings. When used in a pilot study in an LRS, the accuracy of NTM met the target of $\pm 0.5^{\circ} \mathrm{C}$ set prior to subject enrolment. This small accuracy range was selected because of the narrow temperature window associated with normothermia and because an inaccurate reading larger than $0.5^{\circ} \mathrm{C}$ can lead thermal shock and increase chances of mortality. ${ }^{6}$ Out of the four system issues reported, two were problems with the interface between the data collection software and the NTM device, one was a connection issue from temperature probe to monitor. On one instance, the belt slipped down the abdomen, resulting in a gap between the temperature probe and the infant. These issues will be addressed in future iterations of the NTM device.

In informal conversations with clinical staff, they reported the NTM device easy-to-use and interpret. Due to the current noise level within the ward, the visual indicators were well received. Additionally, clinical staff valued the continuous digital temperature display, preferring to use the displayed temperature rather than taking axillary temperature during rounds. Research assistants noted that mothers could understand the meaning of the visual indicators, because some expressed concern to the study nurse when warning lights were illuminated.

Other low-cost temperature-monitoring systems have recently been developed and evaluated for use in lowresource areas. Thermospot ( $\$ 12.50$ for 25 stickers on Maternova.net ${ }^{20}$ ) is a disposable sticker that uses liquid crystal technology that changes colour according to surface temperature. ${ }^{21}$ Each sticker can be used for up to 7-10 days, with colour changes indicating whether a baby is normothermic (bright green), hypothermic (pale green/red/black depending on the degree of hypothermia) or hyperthermic (blue). Two studies in LRS reported sensitivity and specificity for hypothermia detection are $88 \%-97.9 \%$ and $97 \%-99.8 \%$, respectively. ${ }^{11}{ }^{12}$ However, these studies are based on defining hypothermia as an axillary temperature $<35^{\circ} \mathrm{C}-35.5^{\circ} \mathrm{C}$, far below the WHO definition of hypothermia. ${ }^{1}$ Additionally, the Thermospot brochure identifies intermediate red and pale green colours between the bright green and black colour changes, which were not reported in the specificity and sensitivity studies. The Bempu Bracelet is a $\$ 30$ disposable device to be used over a 30-day period to detect hypothermia in KMC or at home. The Bempu Bracelet provides audible and visual alarms when the neonate is hypothermic. ${ }^{22}$ A study performed at a stepped down neonatal nursery in India reported Bempu's sensitivity and specificity for hypothermia detection (defined in the study as $<36.5^{\circ} \mathrm{C}$ ) are $98.6 \%$ and $95 \%$, respectively. ${ }^{13}$

Unlike NTM, neither Thermospot nor the Bempu Bracelet provide a digital display of temperature, ${ }^{21} 22$ hindering clinicians from determining the degree of hypothermia: mild, moderate and severe. ${ }^{1}$ The combination of NTM's continuous digital temperature display and corresponding visual indicators may reduce time to intervention in cases of hypothermia in low-resource hospitals. Visual alerts provide a rapid way for parents and staff to recognise when intervention is needed; the digital temperature display can indicate what type of intervention is necessary. For example, the blue light signal notifies a clinician to attend a hypothermic infant. Once at the infant's bedside, the clinician can tell whether the baby is mildly hypothermic (and intervene by covering the baby, adding an extra blanket or hat ${ }^{1}$ ) or whether the baby is moderately or severely hypothermic (and intervene by placing baby in a radiant warmer, hot cot or incubator when available ${ }^{1}$ ). A recent study used staff education on hypothermia along with equipment repair to reduce neonatal hypothermia in neonatal and KMC wards. ${ }^{23}$ NTM could enhance these initiatives by providing a real-time temperature measurement.

Furthermore, NTM's portability could also allow for continuous temperature monitoring during $\mathrm{KMC}$ in a hospital setting. The belt would secure the temperature probe on the baby's abdomen in the same way as in the NICU, and the monitor could be placed by the mother's bedside. Monitoring is most important during the first days of $\mathrm{KMC}$ to ensure that the thermal treatment is working. The temperature-monitoring in $\mathrm{KMC}$ proposed by the WHO is axillary temperature taken every 6 hours until temperature is stable for 3 days, then decreases to axillary temperature taken every 12 hours. ${ }^{14}$ Knowledge about the effectiveness of KMC, for both nurses and mothers, is often cited as a barrier to its use. ${ }^{24-26}$ The availability of continuous monitoring in KMC could allow for closer observation of babies at risk of hypothermia and increase mothers' advocacy if their baby's temperature is outside the normothermic range.

\section{Limitations of the study}

The study was carried out only at one central hospital under a supervised research protocol with a small sample size. During this pilot study, all standard of care measurements and clinical set up were performed by one trained study nurse. Further research is needed to determine whether the device can be used consistently across users. This device is not yet commercially available.

\section{CONCLUSION}

We developed a low-cost and accurate continuous NTM. Based on performance in this pilot study, the NTM device has the potential to decrease the burden of hypothermia in LRS. The use of NTM in the KMC ward, NTM impact on outcomes and nursing care within the NICU, and the 
accuracy of the device when placed by different users should be explored in further studies.

Acknowledgements The authors would like to acknowledge Prince Mtenthaonga and the clinical staff at QECH neonatal ward for the advice and support given to this pilot study.

Contributors SESS prepared manuscript with support from MKH, RR-K and MH. SESS and MKH conducted laboratory and clinical data collection and analysis. MH, ZMO and RR-K contributed to data interpretation and provided technical advice. $\mathrm{QD}, \mathrm{KK}, \mathrm{ZMO}$ and RR-K contributed to the conception and design of the clinical study. All authors revised the manuscript, provided critical feedback and approved the final version for publication.

Funding The authors have not declared a specific grant for this research from any funding agency in the public, commercial or not-for-profit sectors.

Competing interests None declared.

Patient consent for publication Not required.

Ethics approval The study was reviewed and approved by the Rice University Institutional Review Board (FY2018-42 and FY2017-340), the University of Malawi College of Medicine Research Ethics Committee (COMREC \#2204), and the Malawi National Health Science Research Committee (NHSRC \#1818).

Provenance and peer review Not commissioned; externally peer reviewed.

Data availability statement All data relevant to the study are included in the article or uploaded as supplementary information.

Open access This is an open access article distributed in accordance with the Creative Commons Attribution Non Commercial (CC BY-NC 4.0) license, which permits others to distribute, remix, adapt, build upon this work non-commercially, and license their derivative works on different terms, provided the original work is properly cited, appropriate credit is given, any changes made indicated, and the use is non-commercial. See: http://creativecommons.org/licenses/by-nc/4.0/.

ORCID iD

Rebecca Richards-Kortum http://orcid.org/0000-0003-2347-9467

\section{REFERENCES}

1 World Health Organization. Who | thermal protection of the newborn: a practical guide, 1997. Available: http://www.who.int/maternal child_adolescent/documents/ws42097th/en/ [Accessed 28 Feb 2018].

2 Cartledge PT, Iratubona FU, Dusabimana R, et al. G264 hypothermia prevalence and risk factors in admitted neonates and impact on outcomes at a tertiary neonatal unit, Rwanda: a cross-sectional study. Archives of Disease in Childhood 2019;104:A107

3 Kumar V, Shearer JC, Kumar A, et al. Neonatal hypothermia in low resource settings: a review. J Perinatol 2009;29:401-12.

4 Lunze K, Bloom DE, Jamison DT, et al. The global burden of neonatal hypothermia: systematic review of a major challenge for newborn survival. BMC Med 2013;11:24.

5 Mullany LC. Neonatal hypothermia in low-resource settings. Semin Perinatol 2010;34:426-33.

6 Amadi HO, Olateju EK, Alabi P, et al. Neonatal hyperthermia and thermal stress in low- and middle-income countries: a hidden cause of death in extremely low-birthweight neonates. Paediatr Int Child Health 2015;35:273-81.

7 Lunze K, Hamer DH. Thermal protection of the newborn in resourcelimited environments. J Perinatol 2012;32:317-24.
8 Laptook AR, Salhab W, Bhaskar B, et al. Admission temperature of low birth weight infants: predictors and associated morbidities. Pediatrics 2007;119:e643-9.

9 de Almeida MFB, Guinsburg R, Sancho GA, et al. Hypothermia and early neonatal mortality in preterm infants. $J$ Pediatr 2014;164:271-5.

10 Carns J, Kawaza K, Quinn MK, et al. Impact of hypothermia on implementation of CPAP for neonatal respiratory distress syndrome in a low-resource setting. PLoS One 2018;13:e0194144.

11 Green DA, Kumar A, Khanna R. Neonatal hypothermia detection by ThermoSpot in Indian urban slum dwellings. Arch Dis Child Fetal Neonatal Ed 2006;91:F96-8.

12 Shreshta M. Comparison of liquid crystal device -thermospot with low reading axillary thermometer in detecting neonatal hypothermia |. Pediatric Oncall Journal 2010 https://www.pediatriconcall.com/ pediatric-journal/view/fulltext-articles/322/J/0/0/126/0 (accessed 24 Aug 2018).

13 Tanigasalam V, Vishnu Bhat B, Adhisivam B, et al. Hypothermia detection in low birth weight neonates using a novel bracelet device. $J$ Matern Fetal Neonatal Med 2019;32:1-4.

14 WHO. Kangaroo mother care: a practical guide. WHO, 2003. Available: http://www.who.int/maternal_child_adolescent/ documents/9241590351/en/ [Accessed 27 Aug 2018].

15 Cho E-S, Kim S-J, Kwon MS, et al. The effects of kangaroo care in the neonatal intensive care unit on the physiological functions of preterm infants, Maternal-Infant attachment, and maternal stress. $J$ Pediatr Nurs 2016;31:430-8.

16 Cleveland L, Hill CM, Pulse WS, et al. Systematic review of Skin-toSkin care for full-term, healthy newborns. J Obstet Gynecol Neonatal Nurs 2017:46:857-69.

17 Conde-Agudelo A, Díaz-Rossello JL. Kangaroo mother care to reduce morbidity and mortality in low birthweight infants. In: The Cochrane Library. John Wiley \& Sons, Ltd 2016.

18 World Health Organization. Who recommendations on interventions to improve preterm birth outcomes, 2015. Available: http://www. who.int/reproductivehealth/publications/maternal_perinatal_health/ preterm-birth-highlights/en/ [Accessed 4 Jul 2018].

19 International Standard Organization. Medical electrical equipment - part 2-56: particular requirements for basic safety and essential performance of clinical thermometers for body temperature measurement (iso standard No. 80601-2-56:2009 (en)), 2009. Available: https://www.iso.org/obp/ui/\#iso:std:iso:80601:-2-56:ed-1: v1:en [Accessed 4 Jul 2018].

20 Maternova Inc. ThermoSpot stick-on reusable newborn thermoindicators ( 25 per tin). Maternova Inc. Available: https:// maternova.net/products/thermospot-stick-on-reusablethermoindicators-for-newborn-set-of-25 [Accessed 27 Aug 2018].

21 Zeal J, Fripp R. Introducting the ThermoSpot a non-invasive hypothermia indicator for newborns, infants and children. Available: http://mnhtech.org/uploads/ThermospotBrochure.pdf

22 Bempu Health. Technical specifications of the Bempu hypothermia device, 2016. Available: https://www.viaglobalhealth.com/ wp-content/uploads/2016/03/ENG022-BEMPU-TechnicalSpecifications-V2.pdf

23 Mackenzie FD, Shepherd K, Rukabyarwema JP, et al. G265 neonatal hypothermia - still a serious problem in a low-income country. Archives of Disease in Childhood 2019;104:A107-8.

24 Morgan MC, Nambuya H, Waiswa P, et al. Kangaroo mother care for clinically unstable neonates weighing $\leq 2000 \mathrm{G}$ : is it feasible at a hospital in Uganda? J Glob Health 2018;8:010701.

25 Chan G, Bergelson I, Smith ER, et al. Barriers and enablers of kangaroo mother care implementation from a health systems perspective: a systematic review. Health Policy Plan 2017;32:1466-75.

26 Kenanga Purbasary E, Rustina Y, Budiarti T. Increasing confidence and ability in implementing kangaroo mother care method among young mothers. Compr Child Adolesc Nurs 2017;40:1-7. 